\title{
GEOGRAPHICAL COUPLING OF THE LOCATION'S ACTIVITY IN CYBERSPACE AND AGGLOMERATION OF BUSINESS SERVICE ENTERPRISES
}

\author{
Jian $\mathrm{Wu}^{1}$ and Sheng Qian ${ }^{2}$ \\ ${ }^{1,2}$ Management School, Hangzhou Dianzi University, Hangzhou, China
}

\begin{abstract}
Cyberspace is the new geographical space formed in the virtual digital world which is different from the traditional geographical system. There are some debates that whether Cyberspace lead to further spatial divergence of economic activities or not. Based on existing related research achievements this paper studies the Cyberspace's influence on the spatial distribution of business services, puts forward some hypothesizes about the relationship between the Cyberspace active location and the agglomeration of business services enterprises. By some empirical method, it measures the spatial coupling of location's activity in Cyberspace and the business service enterprises' agglomeration, and the econometric model is established to test the hypotheses. It finds that there is a high coupling relationship of location's Cyberspace activity degree and spatial agglomeration of business services.
\end{abstract}

\section{KEYWORDS}

IT, Cyberspace, Active Location, Agglomeration, Business Service Enterprise

\section{INTRODUCTION}

With the development of information technology, a new space is formed in the digital world different from the traditional geographic space[1][2][3][4], which is called Cyberspace in the literature research, and it is referred to as Cyberspace, Cyberspace[5][6], or network information space[7][8]. With the rapid development of information technologies, our daily life has become deeply dependent on cyberspace[9]. In the perspective of economic geography, the biggest difference between the geographic space and Cyberspace is that the traditional concept of geographical space is based on physical distance, transport infrastructure and tangible material flow. Distance is the most important factor which influences spatial distribution; the Cyberspace is based on information infrastructure, information resources, and intangible information flows, and in many respects the decisive role of distance from the spatial distribution of economic activities has been severely weakened[10].With the decline of the importance of physical location factors such as distance in Cyberspace, a series of changes are bound to occur in enterprises' location selection. Compared with the manufacturing industry, the service industry is less affected by physical location factors such as transportation costs, and its location choice is more diversified and flexible, and the exploration of service industry location theory and its model is imminent[11]. The most important change concerning cyberspace has been its permanent and instant availability to users through broadband services[12].This article focuses on the relationship between Cyberspace and location of business service industry, and studies the relevance of location's activity in Cyberspace and spatial location of business service industry.

David C. Wyld et al. (Eds) : CSITY, DTMN, NWCOM, SIGPRO - 2018

pp. 17-30, 2018. (C) CS \& IT-CSCP 2018

DOI : $10.5121 /$ csit.2018.81102 


\section{LITERATURE REVIEW}

Some scholars tried to define the concept of Cyberspace. Gibson (1984) first proposed the concept of network space[13]. He took that Cyberspace as a huge network based on network connections. It consists of geographically dispersed multiple independent computers which are interconnected by communication lines, essentially it is a computer network information system. Jiang \& Ormeling (1997) defines it as a computer-generated landscape; it is the virtual space of the global computer network; it connects all people, computers and various information resources in the world through a network[14]. Zeng Guoping (1998) believed that Cyberspace is a virtual space where the Internet realizes global computer networking and creates social life and communication through the transportation, storage, and processing of digital information[15]. Li Jiang and Duan Jie (2002) put forward that based on the comprehensive application of computer technology, modern communication network technology, and virtual reality technology, Cyberspace is a new space for people to socialize and communicate[16]. He Guosong (2006) defines Cyberspace as a computer-generated landscape, a virtual space in a global computer network that connects all people, computers, and sources of information in the world[17]. Ning(2018) points out Cyberspace is the digital world created based on traditional physical, social, and thinking spaces (PST) but in turn makes a great difference on PST[18]. In summary, existing researches have not yet formed a clear definition of Cyberspace, it basically agrees with its connotation that the Cyberspace is based on the use of information technology and forms a virtual non-material world through the long-distance transmission method of the network. It is a new form of space.

Some scholars studied the structural characteristics of Cyberspace. Batty's (1997) research on virtual geography revealed the geographical attributes of Cyberspace, and pointed out that the space and location in computer nodes and computer networks are formed by the cyclic development relationship of real place, computer space, internet and network location. [19] Cai et al. (1999) divided Cyberspace into four layers: physical layer, network layer, application layer, and knowledge and behavior layer[20]. Shiode (2000) also stratified the Cyberspace to the real world as the basis layer; above the basis layer is he infrastructure layer for electronic communications which consists by the material infrastructure of information technology; and the third layer is metaphorical space layer, such as multimedia content and network super links; the top layer is the three-dimensional virtual city and virtual places[21]. Feng Zhen (2004) believed that the development of information technology forms a virtual space that corresponds to the real space[22]. Graham(2013) focused on the usage of the 'cyberspace' metaphor and outlines why the reliance by contemporary policy makers on this inherently geographic metaphor matters[23]. The Cyberspace is largely rooted in physical space and location. The two often merge with each other, but there are still significant differences. From the above analysis of the layers of Cyberspace structure, the Cyberspace is a fusion of digital space and geospatial space, including communication facilities and internetworks responsible for information production and transmission, as well as the invisible digital space made up by intangible information that flows between information nodes. Therefore, Cyberspace is a hybrid space composed of information infrastructure and information resources distributed geographically, and intangible information flows in virtual space.

Some scholars studied the elements of Cyberspace. Feng Zhen (2004) compared the constituent elements of the industrialization era and the information era economy[24]. In the era of information economy, the continuous advancement of information technology has given new meanings to the elements of the original spatial structure and created new spatial combination's mode. Hai Jiao (2008) combined the elements of point, line and surface in spatial structure, and presented the specific spatial economic agglomeration type for each combination[25]. Kitchin (2015) argued that geography continues to matter, both off- and online[26]. Based on the analysis 
of existing literature, this paper summarizes the constituent elements of geographic space and Cyberspace, and compares the sources of competitive advantage of the constituent elements, as shown in the table.

Table 1. Elements of Geographic Space and Cyberspace

\begin{tabular}{|c|l|l|l|l|}
\hline & $\begin{array}{l}\text { Geospatial } \\
\text { components }\end{array}$ & $\begin{array}{l}\text { Competitive } \\
\text { Advantage }\end{array}$ & $\begin{array}{l}\text { Cyberspace } \\
\text { component }\end{array}$ & $\begin{array}{l}\text { Competitive } \\
\text { Advantage }\end{array}$ \\
\hline point & $\begin{array}{l}\text { Economic } \\
\text { centre }\end{array}$ & $\begin{array}{l}\text { Economic resources } \\
\text { gathering }\end{array}$ & information Centre & $\begin{array}{l}\text { Information resources } \\
\text { gathering }\end{array}$ \\
\hline line & $\begin{array}{l}\text { Traffic } \\
\text { network }\end{array}$ & $\begin{array}{l}\text { Geographic } \\
\text { reachability }\end{array}$ & $\begin{array}{l}\text { Communication } \\
\text { network }\end{array}$ & $\begin{array}{l}\text { Information } \\
\text { accessibility }\end{array}$ \\
\hline surface & $\begin{array}{l}\text { Economic } \\
\text { belt }\end{array}$ & $\begin{array}{l}\text { Economic radiation } \\
\text { ability }\end{array}$ & $\begin{array}{l}\text { The virtual space } \\
\text { formed by } \\
\text { information flow }\end{array}$ & $\begin{array}{l}\text { Information flow } \\
\text { radiation capabilities }\end{array}$ \\
\hline
\end{tabular}

There is some debate in academic research about the spatial effects of Cyberspace. Some scholars are pessimistic about the prospects of the city and believe that information technology indicate the role of city as a transportation node gradually disappear, and it will bring about the end of cities and agglomeration[27]. And they believed that the first three advantages in Cyberspace are weakened by the important factors that determine the location of enterprises and economic activities in traditional location theory, such as natural advantages, agglomeration economies, and transportation costs[28]. Jungyul, Tschangho \& Hewings (2002) found that information technology is attractive and has spillover effect, and concentration dominant in Chicago area[29]. Kumar (2007) believed that the Internet reduces transportation costs and enables organizations in far geographically distant to share information at any time, and it leads distance to death and economic activity further decentralized[30]. Other scholars pointed out that the Internet is similar to a freeway. The "Siphon effect" of highways has made the underdeveloped rural economy a dead-living region. The same logic may also apply to the Internet[31].Information technology actually enhances the city's function. The effect makes the city more important and more powerful[32]. Hall (1999) explained why the high-end service industry would gather at the core of a few large cities through models and conducted empirical research[33]. The results showed that financial and business services, supranational organizations, and multinational corporate headquarters (originating and controlling functions), creative and cultural industries and tourism are mainly concentrated in the world cities. Some other scholars believe that the Internet is not only a supplement to the city but also a substitute for the city[34]. It can be seen that the impact of Cyberspace on the service industry has not yet been finalized, and the conclusions drawn from studies on different types of service industries are not the same. It is necessary to specifically analyse the impact of Cyberspace on the location choice of the service industry based on industry characteristics for the subdivided industries.

Digital space methods are used to study Cyberspace inter-location relationships. Devriendt (2008) distinguishes two kinds of Cyberspace research methods: content-based analysis (CBA) and structure-based analysis (SBA)[1]. The CBA uses the information found on the World Wide Web to examine the links between cities. The hyperlinked data in search engines are used by CBA researchers to study urban spatial relationships[35]. Although the search engine is far from perfect, it still provides the largest, real-time updated, comprehensive, real-time database that meets research goals[36]. Brunn (2003) used hyperlink data from search engines to test the connections between cities in Asia and Europe[37]. And Moscow, Istanbul, Tehran, and Beijing became the centers of digital connections between Asia and Europe. Williams \& Brunn (2005) classified 197 cities based on information derived from search engines and portrayed the connections between the largest cities in Asia [38]. Devriendt (2008) uses hyperlinks to analyse information networks between European city pairs[35]. London, Paris, and Berlin are the most 
digitally connected cities. SBA regards the level of website links to each other as a Cyberspace structure. The analysis of website structure is a common method used by SBA researchers to measure digital connections in Cyberspace. Park (2005) obtained broadband connection data from 63 countries and website data from 47 countries, examined the structure of the Internet, and found that the United States is a linking centre country[39]. Brunn (2005) used Google's search engine's URL site data to search and rank 199 world capitals and divide them into five sequences[40]. Huiping Zhang (2011) applied network content analysis method, link analysis method and network influence factor theory to propose a set of information measurement indicators for evaluating the websites of municipal governments[41]. Guangyong Zhai (2010) used nine indicators such as the total number of links and the number of external links to explore the widespread phenomenon of "information isolated islands" and its causes[42]. Mingfeng Wang (2007) established a system of indicators for evaluating the development of the Internet in cities based on the data of several important portals, and also classified the Internet use scale, the level of development and extroversion of Internet use in Chinese cities above prefecture-level cities[43][44]. It can be seen that the study of Cyberspace examined the structure of invisible virtual worlds, such as Internet hyperlinks, the structure of engine search, and the amount of email. Cyberspace research does not focus on physical infrastructure. It focuses on the production, launch, transportation, and consumption of vast intangible information between locations, interested in determine the flow of information between locations. It also analyses quantitatively and qualitatively what kind of information flows and how it flows.

From the results of research on the spatial effects of Cyberspace, the focus of attention is mainly on the spatial attributes of information flow and information resources. Some achievements have also been made in the interaction between Cyberspace and geospatial space, but so far the Cyberspace has become more economically active, the influence of spatial distribution is still rarely involved. This paper attempts to study the influence of Cyberspace on the geographical distribution of economic activities, especially the spatial distribution of business service industries. On the basis of literature review, the relevance of location activity in Cyberspace and location business service industry agglomeration is measured. It is believed that in the Cyberspace, the more digital connections between space units and other units, the more active the unit is in Cyberspace. Therefore, this paper defines the location's activity of Cyberspace as the degree of digital connection with other spatial units.

\section{HYPOTHESIS}

The impact of information technology brings changes in the function and shape of geospatial points and lines. In traditional geospatial space, nodes often assume the role of growth poles in the entire spatial structure system, and they are the growth centres of the region. Their scale depends on the size of the hinterland. The development of information technology has enabled cities to gradually realize the transition from traditional transportation hubs to information hubs. In the Cyberspace, information flow reshapes the urban system, prompting the transition of regional nodes from the production and consumption centres of traditional industrial products to the centre of information production and transmission and knowledge innovation. The node plays the role of regional knowledge base, information base, and source of innovation. The role and function of the node depends more on the type and quantity of inflow and outflow of information and knowledge. The information flow determines the size and importance of the city. Therefore, the nodes in the traditional geographical space are regional growth centres and are the gathering places of regional economic resources. In the modern Cyberspace, nodes are the regional information centres and the gathering places of regional information resources. In the traditional geographical space, the transportation network is the line connecting spatial nodes. A good transportation network improves the regional investment environment, changes the industrial layout and industrial structure along the line, integrates various economic resources in the region, 
and it has a very important role in promoting the construction of the regional economy. The Internet is the world's most important information flow carrier and infrastructure in the information age. It has constructed a new social economic model and a cyber virtual space. In Cyberspace, the Internet is the line that connects the nodes of Cyberspace. Information flow has become an important element of economic and social systems. The emergence of the information economy has reconstructed the city's competitive advantages in many areas and has become an important driving force for regional development. In these regions, the dominant infrastructure is not freeways, ports, railroads, or airports, but fibre optic networks that connect the world. Different levels of connectivity have created a global polarization of information flow and Internet connectivity, forming the archipelago economy: Cities with higher access to information gain enormous economic benefits from nodes that act as information flows, logistics, and people flow, and many regions lack an access to information and they become the edge of the information world economy. Therefore, the lines of traditional geospatial space are constituted by transportation networks, and geographic accessibility is an important competitive advantage of location; the lines of modern Cyberspace are constituted by the Internet, and information accessibility is an important competitive advantage of location.

As mentioned before, the extensive application of the Cyberspace breaks through the space-time constraints of traditional geography, and it makes geographical research into an open field full of information flow, and in particular a new standard for the study of information geography, resulting in changes in geographical thinking and philosophy. While the Cyberspace weakens the importance of the original geographic elements, it also adds a series of new elements to geography, gives new meaning, and provides new research content. In the current global network structure of the Cyberspace, regions in the information flow will gain advantages and create value and gain wealth, and areas that are out of the flow of information will lose their advantages. In this process, the region's position in Cyberspace and the resulting concentration and proliferation of the flow of production factors directly determine the advantages of a region. At the same time, the flow of space also enhances the advantages and information flow in certain specific areas, resulting in new regional advantages. The decentralization of economic activities caused by globalization has greatly increased the necessity of strengthening the control and management functions of the centre. As a result, the high-level producer services, such as finance, accounting, advertising, and consulting, which are responsible for the central control functions, will be highly concentrated in global cities. It is an era of fierce competition. The speed of dissemination of knowledge and information is really fast. The productive service industry needs to maintain its leading edge in information resources, and the storage and updating of its own information is of utmost importance. The advantaged areas with high degree of activity in the Cyberspace are the distribution centres of knowledge and information. The smooth flow of information and knowledge can help the enterprise information and knowledge to be updated in a timely manner and help the enterprise to remain competitive. It can be inferred that the business services industry tends to gather in large cities with big information flow, and it is easy to control the decentralized economy in the context of globalization. Based on the above analysis and discussion on the influence of the Cyberspace activity on the spatial distribution mechanism of the business service industry, this paper proposes:

Hypothesis 1 : The higher degree of Cyberspace activity has a positive effect on the number of business service enterprises agglomerate in space units.

At the same time, it is necessary to realize that there are many types of business services, and the information sensitivities of companies with different types of main business are different. In order to deeply analyse the influence of the location's activity in Cyberspace on the business service enterprises agglomeration, and according to different business types of the company, this paper divides the business service enterprises into management consulting enterprises (including 
business management, certification, legal, consulting, investment, registration, training, testing, insurance and program enterprises, etc), advertising design enterprises (including advertising, design, exhibition, promotion, image, packaging, etc.) and agency enterprises (including branding, labour, translation, headhunting, travel, leasing, outsourcing, etc ). Here are the following assumptions:

Hypothesis 2: A higher degree of Cyberspace activity has a positive effect on the number of management consulting business service companies agglomerate in space unit.

Hypothesis 3: The high degree of Cyberspace activity has a positive impact on the number of advertising design business service companies agglomerate in space unit.

Hypothesis 4: The high degree of Cyberspace activity has a positive effect on the number of mediation agency business service companies agglomerate in space unit.

\section{EMPIRICAL RESEARCH}

\subsection{Measurement Method and Evaluation Index Selection}

This paper measures the degree of geographic coupling between the location's activity of Cyberspace and the agglomeration of business services enterprises, and then establishes the empirical econometric model and makes empirical study to examine the influence of Cyberspace location's activity on the concentration of business services enterprises. In general, the smaller the spatial unit is, the easier it is to reflect the regularity and difference of the inner space of the city. China's industry and population census are usually based on blocks (townships, towns) as the smallest unit of statistics, with blocks as the basic unit, can make cities comparable, and the accuracy of the data is also high, so it is most commonly used. Therefore, this paper uses blocks as the microscopic spatial unit for statistical analysis. Regression analysis variables mainly include explanatory variables the distribution of business service industry, and the explanatory variables the Cyberspace location's activity. At the same time, introduces the control variables of economic variables as local markets, location accessibility, knowledge spillovers, industrial chains, and government.

The explanatory variable of the regression analysis is the Shanghai business service enterprises' agglomeration. In this paper, the total number of statistical data from the business administration government department is used to select valid business service enterprises data which spatial location can clearly been defined. Because a large amount of data address information is not standardized, it is impossible to directly determine its spatial location. Therefore, this part of the work has taken a lot of time and energy. The final statistics obtained 5,775 samples of business service enterprises. The samples were classified, and statistics were made based on the sample addresses. A sample space attribute database was established. Find the address of each business service company and categorize it by its block.

The main explanatory variable is the Cyberspace location's activity. The literature on the distribution of Cyberspace within the city is still very few. Only a few scholars have begun to get involved[44]. Zook $(1998,2000)$ has illustrated the spatial distribution of business domain names in metropolitan areas in the United States (such as New York City and San Francisco)[45][46]. The results show that these domain names are obviously concentrated in the city's central business district. The study by Malecki (2000) has similar conclusions[47]. The research team headed by Moss (1999) designed an evaluation framework for urban comprehensive portals to compare the space design of major cities in the United States and proposed optimization measures for urban Cyberspace[48]. After summarizing several models of future Internet development, 
Moss (1999) discussed the construction of the community-level website, finally put forward the government information strategy for urban development [49]. Since many portal sites on the micro-level spatial unit blocks have not been established, most of the websites established belong to the district and county domain names, causing the website structure analysis method to fail. This paper uses the hyperlink method of search engine to search for the number of hyperlinks of Shanghai's 253 blocks.

Control variables includes economic level, local market, location accessibility, knowledge spillover, industry chain and government. The measurement index and data sources for each variable are as follows.

Table 2: Variable measurement index and Sources of Data

\begin{tabular}{|c|c|c|}
\hline variable & Measurement index & Data Sources \\
\hline $\begin{array}{l}\text { business } \\
\text { services } \\
\text { distribution }\end{array}$ & $\begin{array}{l}\text { space unit business service } \\
\text { industry concentration degree }\end{array}$ & $\begin{array}{l}\text { Number of business services companies in each } \\
\text { unit of space }\end{array}$ \\
\hline $\begin{array}{l}\text { Cyberspace } \\
\text { activity }\end{array}$ & $\begin{array}{l}\text { Spatial unit digital } \\
\text { connections }\end{array}$ & hyperlinks number of spatial unit \\
\hline economic level & land price & $\begin{array}{l}\text { According to the " } 2010 \text { Shanghai Standard Land } \\
\text { Price Correction System", the statistics of the } \\
\text { land unit's land price level from } 0 \text { to } 9\end{array}$ \\
\hline local market & population density & spatial unit's population per unit area \\
\hline $\begin{array}{l}\text { location } \\
\text { accessibility }\end{array}$ & $\begin{array}{l}\text { number of transport hubs } \\
\text { within the spatial unit }\end{array}$ & $\begin{array}{l}\text { According to the "Layout Plan of Shanghai's } \\
\text { Comprehensive Passenger Transport Hubs" , } 145 \\
\text { traffic hubs in Shanghai are assigned to five } \\
\text { levels from } 4 \text { to } 0 \text {, and the number of traffic hubs } \\
\text { per spatial unit is calculated. }\end{array}$ \\
\hline $\begin{array}{l}\text { Knowledge } \\
\text { spillover }\end{array}$ & university units in spatial unit & $\begin{array}{l}\text { According to } 101 \text { universities and branch } \\
\text { campuses, calculates the universities and their } \\
\text { campuses within each spatial unit }\end{array}$ \\
\hline Industry chain & park within spatial unit & $\begin{array}{l}\text { Check the location of } 63 \text { economic development } \\
\text { zones in Shanghai, and calculates the number of } \\
\text { economic parks and development zones in each } \\
\text { spatial unit }\end{array}$ \\
\hline government & $\begin{array}{l}\text { government agencies within } \\
\text { the spatial unit }\end{array}$ & $\begin{array}{l}\text { Whether there is an urban county government } \\
\text { within each spatial unit }\end{array}$ \\
\hline
\end{tabular}

\subsection{Selection of statistical and econometric models}

The geographic interrelation coefficient reflects the location relationship between the two economic factors in geographical distribution. Judging the consistency of the spatial distribution of the two factors by the similarity degree in spatial structure, the formula is:

$G=100-\frac{1}{2} \sum_{i=1}^{n}\left|S_{i}-P_{i}\right|$

In the formula, $\mathrm{G}$ is the geographic interrelation coefficient, $\mathrm{n}$ is the number of blocks, and $S_{i}, P_{i}$ are the percentage of each economic factor in each block. It indicates that the geographic interrelation of the two economic factors is relatively close, and the geographic distribution is relatively uniform when $\mathrm{G}$ is large; when the $\mathrm{G}$ value is small, it indicates that the two economic factors are not closely related to each other, and the geographical distribution is relatively different. This paper uses geographic interrelation coefficient to measure the relationship between Shanghai's business service industry agglomeration and Cyberspace location's activity. 
When the dependent variable is a discrete integer, it is a counting variable, its value is small or sometimes zero, meanwhile the explanatory variables are mostly qualitative variables, the application of the counting model should be considered. The Poisson model is widely used in the counting model[50]. Wu (1999) used the model to study the selection of foreign-owned enterprises within Guangzhou city[51]; Figueiredo (2002) studied the selection of US manufacturing units in county-level space units[52]; Hua Zhang et al. (2007) applied this model to study the relationship between location selection and accessibility of foreign-funded enterprises in Beijing[53]. However, Zhang Hua did not further verify whether the Poisson model was suitable, and did not verify whether the harsh conditions such as the conditional mean and the conditional variance were meet. Under the condition of applying the counting model, it is necessary to choose between the Poisson model and the negative binomial distribution model. In general, the conditions of the Poisson model are difficult to meet. This paper uses the negative binomial distribution model for estimation. Weiguo $\mathrm{Lu}$ and Wen Chen (2009) used blocks (established towns) as spatial units to analyze the location choices of Nanjing manufacturing companies using the negative binomial distribution model[54]. The log-likelihood function of the negative binomial distribution is:

$$
L(\beta, \eta)=\sum_{i=1}^{N}\left\{y_{i} \ln \left[\eta^{2} \lambda_{i}\right]-\left(y+1 / \eta^{2}\right) \ln \left(1+\eta^{2} \lambda_{i}\right)+\ln \Gamma\left(y_{i}+1 / \eta^{2}\right)-\ln \left(y_{i} !\right)-\ln \Gamma\left(1 / \eta^{2}\right)\right\}_{\mathrm{T}}
$$

he above parameters $\eta^{2}$ are estimated together with the parameter $\beta$. When the degree of dispersion of the data is so large that the conditional variance is greater than the conditional mean, a negative binomial distribution model is usually used. In this way, the conditional variance is greater than the conditional mean, and the following moment conditions hold:

$$
\begin{aligned}
& E\left(y_{i} \mid X_{i}, \beta\right)=\lambda_{i} \\
& \operatorname{var}\left(y_{i} \mid X_{i}, \beta\right)=\lambda_{i}\left(\eta^{2} \lambda_{i}\right)
\end{aligned}
$$

Among them, $\eta^{2}$ measures the degree of conditional variance exceeds the conditional mean.

If the distribution of dependent variables cannot be assumed to be Poisson, then quasi-maximum likelihood estimation (QML) is performed under other distribution assumptions. Even if the distributions are incorrectly set, these quasi-maximum likelihood estimators can produce a consistent estimate of the parameters for which the conditional mean is set correctly. For these QML models, the requirement for consistency is that the conditional mean is set correctly[45].Therefore, the parameters of the QML estimation of the negative binomial distribution are used to estimate the parameters. For the fixed $\eta^{2}$ parameter, the quasi-maximum likelihood estimation of the parameter $\beta$ can be obtained. If set correctly, the quasi-maximum likelihood estimator remains consistent even if the conditional distribution of y disobeys the negative binomial distribution.

\subsection{Empirical test results and analysis}

According to the statistical results, the spatial concentration of business services is still concentrated in the central of city. The largest number of business service companies are Xujiahui Block and Tianlin Xincun Block in Xuhui District, Tianmu West Road Block in Zhabei District, and Lujiazui Block in Pudong New Area. As shown in Figure 1 below. 
In this paper, it use the hyperlink method of search engine to search for the number of hyperlinks of 253 blocks in Shanghai and find out the Cyberspace in Shanghai. The result is shown in Figure 1. As can be seen from the figure, Shanghai's more active location in Cyberspace centers are concentrated in several central districts such as Huangpu District, Yangpu District and Jing'an District. Chongming County, Pudong New Area, Songjiang District, Qingpu District and other suburban districts and counties are less active in Cyberspace.
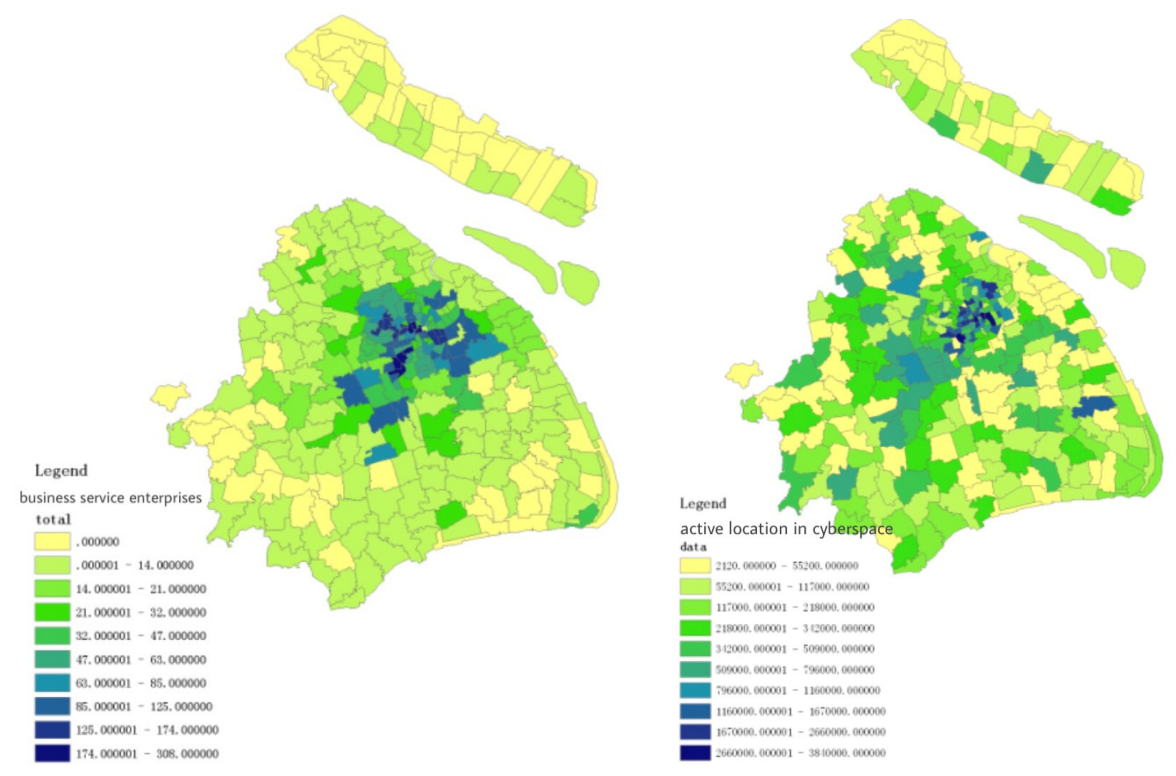

Figure 1. Overall spatial distribution of business services and Cyberspace in Shanghai

In this paper, the geographic interrelation coefficient of Shanghai's business service industry and Cyberspace activity is used to measure the geographic relationship, and the geographic interrelation coefficient of business service industry clustering and location's activity is shown in Table 3. On the whole, the geographic interrelation coefficient between spatial concentration of business services and activity of Cyberspace is relatively high, indicating that there is a positive correlation between geographical distribution of them. For different types, the geographic interrelation coefficient of advertising design and information service industries are relatively low, and management consulting is relatively high.

Table 3: Geographical Interrelation Coefficient of Unit Business Service Agglomeration and Location's Activity in Cyberspace

\begin{tabular}{|c|c|}
\hline & Geographical contact rate with location activity \\
\hline All business services & 75.94611 \\
\hline Management consulting & 69.30087 \\
\hline Advertising design & 74.91884 \\
\hline Agency Agents & 72.38692 \\
\hline
\end{tabular}

Use Stata software to perform negative binomial regression analysis with the data. The analysis results are shown in Table 4. From the regression analysis, the location's activity in Cyberspace 
significantly positively affects the overall agglomeration of business services in Shanghai and the sub-industry agglomeration. As far as business types are concerned, the degree of location's activity has less impact on management consulting and intermediary agency companies, and has a greater impact on advertising design companies. Through the regression analysis results, the following conclusions can be drawn: there are different influence of location's activity in Cyberspace when company types are different. The spatial distribution of management consulting business service companies is the least affected by the location's activity in Cyberspace, and intermediary agency companies are most affected.

Table 4: Negative Binomial Regression Results

\begin{tabular}{|c|c|c|c|c|}
\hline & overall & $\begin{array}{l}\text { Management } \\
\text { consulting }\end{array}$ & $\begin{array}{l}\text { Advertising } \\
\text { Design }\end{array}$ & Agents \\
\hline \multirow{2}{*}{ Cyberspace activity } & $2.82 \mathrm{e}-07 * * *$ & $2.22 \mathrm{e}-07 * *$ & $2.62 \mathrm{e}-07 * *$ & $2.33 \mathrm{e}-07 * *$ \\
\hline & $(2.67)$ & $(2.11)$ & $(2.52)$ & ( 2.14 ) \\
\hline \multirow{2}{*}{ Local market } & $-1.90 \mathrm{e}-07$ & $1.03 \mathrm{e}-07$ & $-7.15 \mathrm{e}-07$ & $-6.97 \mathrm{e}-07$ \\
\hline & $(-0.19)$ & $(0.10)$ & $(-0.67)$ & $(-0.50)$ \\
\hline \multirow{2}{*}{ economic level } & $.352379 * * *$ & $.3244841^{* * *}$ & $\begin{array}{l}.3376388 * * \\
*\end{array}$ & $.3412439 * * * *$ \\
\hline & $(10.85)$ & $(9.76)$ & $(10.43)$ & $(9.79)$ \\
\hline \multirow{2}{*}{ Location accessibility } & $.3524257^{* * *}$ & $.3403458^{* * *}$ & $\begin{array}{l}.3096915 * * \\
*\end{array}$ & $.3498424^{* * *}$ \\
\hline & $(11.35)$ & $(10.69)$ & $(9.72)$ & $(10.94)$ \\
\hline \multirow{2}{*}{ Knowledge spillover } & -.0135859 & -.0332696 & -.0537594 & -.0025649 \\
\hline & $(-0.22)$ & $(-0.56)$ & $(-0.88)$ & $(-0.04)$ \\
\hline \multirow{2}{*}{ Industry chain } & $.2940056^{* *}$ & .0601844 & $\begin{array}{l}.3994586 * * \\
*\end{array}$ & $.2719905^{*}$ \\
\hline & $(2.29)$ & $(0.44)$ & $(3.16)$ & ( 1.94$)$ \\
\hline \multirow{2}{*}{ government } & $.5148045^{* *}$ & $.6646881 * * *$ & .2805462 & $.5259932 * *$ \\
\hline & $(2.44)$ & ( 3.09$)$ & $(1.35)$ & $(2.42)$ \\
\hline \multirow{2}{*}{ constant } & .8400997 & -.008621 & .1476751 & -.4340789 \\
\hline & $(6.86)$ & $(-7.02)$ & $(3.16)$ & $(-2.98)$ \\
\hline Number of samples & 253 & 253 & 253 & 253 \\
\hline LR & 306.49 & 284.90 & 264.02 & 270.53 \\
\hline Significant & 0.0000 & 0.0000 & 0.0000 & 0.0000 \\
\hline $\mathbf{P}-\mathbf{R}^{2}$ & 0.1109 & 0.1346 & 0.1204 & 0.1410 \\
\hline
\end{tabular}

The Z-statistics are in parentheses, *,**, and *** are $1 \%, 5 \%$, and $10 \%$, respectively, and P-R2 is Pseudo R2.

The business services industry is knowledge-intensive, this is the biggest difference between traditional service industries such as catering service and commerce. Business services industry mainly use professional talents and professional knowledge as the main producing factors, and production, application, and dissemination knowledge are the main service processes. It has the feature of talents concentration and innovation. Because of its knowledge-intensive characteristics, the business service industry is in a high-end position in the value chain, and it has a lot of links and a wide range highly value-added. Compared with the traditional manufacturing industry who requires a large amount of land resources, the business service industry is not highly dependent on land and has less requirements on environmental carrying capacity, but it has a strong dependence on urban functions. Its information sensitivity, knowledge intensity and the 
characteristics of innovative services have determined that their main agglomerations are center cities and core urban areas. The business service industry has a higher demand for talent density and information flow, and the strength of the urban function directly affects the flow and concentration of talent and information. Therefore, business service industry does not spread with the development of information technology, in contrast it has concentrated in cities' core where have a high degree of location's activity in the Cyberspace.

\section{CONCLUSIONS}

Hyperlink analysis method was used to evaluate the location's activity of Cyberspace in Shanghai. The results shows that the most active blocks are concentrated in several central areas such as Huangpu District, Yangpu District and Jing'an District. The location's activity in the suburban districts and counties such as Chongming County, Pudong New Area, Songjiang District and Qingpu District are relatively weak. Negative binomial regression is used to empirically investigate the influence of block's activity in Cyberspace on the spatial distribution of business service industry. It is found that the location's activity of Cyberspace has a positive effect on the spatial agglomeration of business services; however, there are different influences due to different types of business. The spatial agglomeration of management consulting business service companies ia the least affected by the location's activity of Cyberspace, and intermediary agency companies is most affected by the activity. It can be inferred that the location's activity in Cyberspace will promote the spatial gathering of the business service industry, but compared with other types of business service industry, the intermediary service business service industry is more likely to gather in the area with more active location. It shows that the business service industry does not spread with the development of information technology, but has been more concentrated in the core urban area with a high degree of activity in the Cyberspace.

\section{REFERENCES}

[1] Devriendt.L, Derudder.B, Witlox.F. Cyberplace and Cyberspace,(2008) " Two Approaches to Analyzing Digital Intercity Linkages”, Journal of Urban Technology, Vol. 15,No. 2, pp5-32.

[2] Devriendt.L, Boulton.A, Brunn.S, Derudder.B, Witlox.F, (2011) “ Searching for Cyberspace: The Position of Major Cities in the Information Age", Journal of Urban Technology, Vol. 18, No. 1, pp7392.

[3] Dodge M . Guesteditorial, (2001) "Cybergeography", Environment and Planning B: Planning and Design, Vol. 28, No. 1, pp1-2.

[4] Dodge M , (1999) “The Geographies of Cyberspace", Centre for Advanced Spatial Analysis working paper series, paper8. University College London,1999.

[5] Luquan Jiang,Zhiren Zou,Rongzeng Liu,Feng Zhen,(2002), “ Development of Cyber Geography in Foreign Countries”, World Geography Research, Vol. 11, No. 3, pp92-98.

[6] Heli Lu, Guifang Liu, (2005) "Research on Geographical Distribution of Cyberspace", Scientia Geographica Sinica,Vol. 25, No. 3, pp317-321.

[7] Zhongwei Sun, Zi Lu, Yang Wang, (2007) "Review and prospect of geography research in network information space", Advance in Earth Sciences, Vol. 22,No. 10, pp1005-1011.

[8] Jie Zhang, Chaolin Gu , Jinkang Du , Yikang Zhou , (2000) "Research progress and prospects of human geography in computer network information space”, Scientia Geographica Sinica, Vol. 20 , No. 4, pp368-374. 
[9] Li F, Li Z, (2017)“Cyberspace-Oriented Access Control: Model and Policies”, IEEE Second International Conference on Data Science in Cyberspace. 26-29.

[10] Zhongwei Sun , Yang Wang, (2011) “Progress and Prospects of Research on Information and Communication Geography in China”, Advances in Geography, Vol. 30, No. 2, pp149-156

[11] Malecki, E.J,(2002) "The Economic Geography of the Internet's Infrastructure", Economic Geography, Vol. 78, No. 4, pp399-424.

[12] Kellerman A, (2015)"Mobile broadband services and the availability of instant access to cyberspace". Environment \& Planning A. Vol.42, No.12, pp2990-3005.

[13] O'Brien R,(1992)Global Financial Integration: The End of Geography, New York: Royal Institute of International Affairs.

[14] Cairncross F, (1997) The Death of Distance. Cambridge,MA : Harvard Business School Press.

[15] Fotheringham A. S, (1997) "Trends in quantitative methods I: Stressing the local”, Progress in Human Geography, Vol. 21, No. 1, pp88-96.

[16] Fotheringham A S,Brunsdon C,(1999) "Local forms of spatial analysis", Geographical Analysis, Vol. 31, No. 4, pp340-358.

[17] Fujii,T, Hartshorn,R.P., (1995) “ The changing metropolitan structure of Atlanta,GA: Locations of functions and regional structure in a multinucleated urban area", Urban Geography, Vol. 16, No. 1, pp680-707.

[18] Ning H, (2018)“General Cyberspace: Cyberspace and Cyber-enabled Spaces” , EEE Internet of Things Journal, Accepted.

[19] Bingham,R.D., Kimble,D., (1995) "Industrial composition of edge cities and downtowns", Economic Development Quarterly, Vol. 9, pp259 -272.

[20] Jian Feng , Yixing Zhou, (2003) "Spatial Structure and Evolution of Urban Societies in Beijing (1982-2000)", Geography Research, Vol. 22, No. 4, pp 465-483.

[21] Zhou Xingxing, (1996) "The suburbanization of Beijing and the thinking it caused", Geographical Sciences, Vol. 16, No. 3,pp198-205.

[22] Zongqing Zong, (2007) Research on spatial structure of commercial activities in Beijing. Ph.D. thesis of Peking University.

[23] Graham M,(2013)“Geography/internet: ethereal alternate dimensions of cyberspace or grounded augmented realities?”. Geographical Journal, Vol.179, No.2, pp177-182.

[24] Jianbin,Chen, Jing Liu, (2007) "Research on Evaluation Method of Enterprise IT Capability Based on Resource Theory”, Management Science, No. 20, Suppl PP: 63-66.

[25] Hao Jiao, Aiqi Zhai , Yang Zhang, (2008) " Measurement and Efficacy of Enterprise IT Capability: Construction and Empirical Research of Local Models”, Journal of Science Studies, Vol. 26, No. 3, pp596-603.

[26] Kitchin R, Dodge M, (2015)“"Placing' Cyberspace: Geography, Community and Identity”, Information Technology, Vol.1, No.2, pp25-46.

[27] Moss,M.L., Townsend, A, (1997) "Tracking the Net: Using Domain Names to Measure the Growth of the Internet in U.S. Cities", Journal of Urban Technology, Vol. 4, No. 3, pp47-60. 
[28] Pan Jianping, Gu Guanqun, Gong Jian,(1997) “ Research on the network operation s of the CERNet backbone”, Journal of Southeast University ( English Edit ion), Vol. 13, No. 1, pp5-11.

[29] Zhang Nannan, Gu Chaolin, (2002) "From the geographical space to the compound space: the urban space under the influence of information networks", Human Geography, Vol. 17, No. 14, pp20-24.

[30] Liu Weidong,(2002) "Discuss About the Development of China's Internet and Its PotentialSpatialInfluence", Geographical Research, Vol. 21, No. 3, pp347 - 356.

[31] Wang Mingfeng, Ning Yuemin, (2006) "Network Advantages of Cities: An Analysis of China's Internet Backbone Network Structure and Node Accessibility", Geography Research,Vol. 25, No. 2, pp193-203.

[32] Zhang Pingyu, Liu Wenxin, Ma Yanji, (2006) "Spatial differences and changes in the development of Internet in Liaoning Province", Economic Geography, Vol. 3, pp447-450.

[33] Batty,M, (1997) “Virtual geography” Futures, Vol. 29, No. 4-5, pp337-352.

[34] Lu Zi, Shu Fang, Wang Ran, (2008) “ Comparison of Realistic Geographic Space and Virtual Network Space in China”, Geographical Sciences., Vol. 28, No. 5, pp601-606.

[35] Boulton,A, Lomme Devriendt, Brunn,L.S., Derudder,B., Witlox,F, (2001) ICT's for mobile and ubiquitous urban infrastructures : surveillance, locative media and global networks. Hershey, PA, IGI Global.

[36] Devriendt, L., Boulton, A., Brunn, S., Derudder, B. \& Witlox, F., (2009) Major cities in the Information World: monitoring cyberspace in real-time. GaWC Research Bulletin 308.

[37] Brunn,S.(2003) "A note on the hyperlinks of major Eurasian cities. Eurasian Geography and Economics”, Vol. 44, No. 4, pp321-324.

[38] Brunn,S., Williams, J., (2005) "Cybercities of Asia: measuring globalization using hyperlinks", Asian Geographer,Vol. 23, No. 1/2, pp121-147.

[39] Park,H.W. ,(2008) “Thelwall,M.Link analysis: Hyperlink patterns and social structure on politicians' Web sites in South Korea", Quality \& Quantity. Vol. 42, No. 5, pp687-697.

[40] Brunn,S.D.,(2005) An E-Classification of the World's Capital Cities: URL References to Web Sites. Idea Group Inc.

[41] Zhang Huiping,(2005) “ Research on Information Metrology Index of Prefecture-level Government Websites", Journal of University of Electronic Science and Technology of China, Vol. 06, pp53-56.

[42] Zhai Guangyong., (2010) "An Empirical Study of Government Websites in the Perspective of Webometrics: An Empirical Study on Information Isolated Islands", Journalism and Communication Studies, Vol. 6, pp39-44.

[43] Wang Mingfeng, Ning Yuemin, Hu Ping, (2007) "Types and Spatial Differences of Internet Development in Chinese Cities", Urban Planning, Vol. 10, pp19-22.

[44] Wang Mingfeng, Ning Yuemin, (2002) "Urban geography in cyberspace: a review and prospect", Advances in Earth Science, Vol. 17, No. 6, pp855-863.

[45] Zook,M.A , (1998) The Web of Consumption:The Spatial Organization of the Internet Industry in the United States. The Association of Collegiate Schools of Planning 1998 Conference, Pasadena,CA , 1998. 
[46] Zook,M.A, (2000) "The web of production : the economic geography of commercial Internet content production in the United States", Environment and Planning A, Vol. 32, pp411-426.

[47] Malecki, E J, (2000) The Internet: A preliminary analysis of its evolving economic geography. Global Economic Geography Conference. Singapore.

[48] Moss,M.L.,Wade,C.,Wong,J.L.,(1999)Municipal government Online:How NYC can Become the Internet City[R]. Prepared for the Office of the Public Advocate for New York and the Accountability Project Inc,New York:Taub Urban Research Center , New York University , .

[49] Moss,M.L.,Wardrip-Fruin,N.,Harrigan,P. (1999)New York City Web Guides : An In-depth Analysis of New York City’s Web Presence. New York:Taub Urban Research Center,New York University.

[50] Gao Tiemei. (2009)Econometric analysis methods and modeling. Beijing: Tsinghua University Press (second edition)

[51] Wu F, (1999) "Intrametropolitan FDI firm location in Guangzhou, China: A Poisson and negative binomial analysis", Annals of Regional Science, Vol. 33, No. 4, PP535-555.

[52] Figueiredo O., Guimaraes P., Woodward D, (2002) Modeling industrial location decisions in U.S. counties. ERSA conference papers, European Regional Science Association

[53] Zhang Hua, He Canfei, (2007) "Location Accessibility and Location Selection of Foreign-funded Enterprises in Beijing”, Geographical Research, Vol. 26, No. 5, pp984-994.

[54] Lu Weiguo, Chen Wen., (2009) "Location Selection of Manufacturing Enterprises and Reconstruction of Urban Space in Nanjing", Acta Geographica Sinica, No. 2, pp142-152.

\section{AUTHORS}

Wu Jian is an Associate Professor at Management School, Hangzhou Dianzi University, China. He got his $\mathrm{PhD}$ degree from the University of Tongji University in 2012. His research interests include IT and its impact to the development of economy and enterprises.

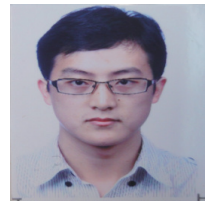

Qian Sheng is a Professor at Management School, Hangzhou Dianzi University, China. His research interests include IT and its impact to the development of economy and enterprises.

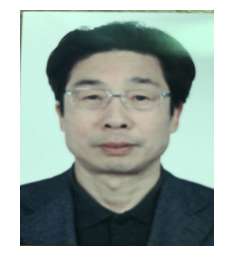

